\title{
A Design of Microstrip Lowpass Filter with Wide Rejection Band and Sharp Transition Band Utilizing Semi-Circle Resonators
}

\author{
Askan ABDIPOUR, Arash ABDIPOUR, N. ALAHVERDI \\ Young Researchers and Elite Club, Kermanshah Branch, Islamic Azad University, Kermanshah, Iran \\ Ashkan_abdipour@yahoo.com,Arash.abdipour@yahoo.com \\ Submitted February 14, 2018 / Accepted July 24, 2018
}

\begin{abstract}
In this paper, a microstrip lowpass filter with $-3 \mathrm{~dB}$ cut-off frequency of $2.1 \mathrm{GHz}$ consisting of three cascaded resonators with different semi-circle patches and four suppressors employing radial stubs has been proposed. To indicate the role of each employed microstrip transmission line in the structure of its resonance cell, the equations of the transfer function and transition zero of the resonator have been calculated, separately. The designed filter has been constructed and tested, and a good agreement between the results of simulation and measurement has been achieved. In the whole rejection region, a return loss better than $+0.28 \mathrm{~dB}$ and a $19.656 \mathrm{GHz}$ stopband bandwidth with high rejection level of $32 \mathrm{~dB}$ have been obtained. Moreover, a flat insertion loss close to zero in the passband and sharp cutoff slope $(203.57 \mathrm{~dB} / \mathrm{GHz})$ can verify the desired frequency response. The proposed filter has a high figure of merit equal to 24241.69.
\end{abstract}

\section{Keywords}

Microstrip lowpass filter, transfer function, transition zero, semi-circle patches

\section{Introduction}

Microstrip lowpass filters (LPFs) are one of the key blocks that are employed widely to suppress undesired frequencies. To meet this purpose, various LPFs have been designed. For example, in [1], loaded radial-shape patches and meandered main transmission line have been used and a microstrip lowpass filter with quasi-elliptic response has been presented, but, this filter has a gradual transition band and low level of suppression. In order to widen the stopband bandwidth of LPFs, several hairpin resonators have been designed [2-6]. By adopting this cell in [2], the stopband region has been extended. However, the circuit occupies a large area and the transition band is not sharp enough. A technique to design a LPF is using radial shaped stubs in the structure of hairpin resonator, which has been carried out in [3], but this method does not have a steep cut-off. In [4], to design a LPF another form of stepped impedance hairpin units have been employed. However, this filter does not have a wide stopband. In [5], another technique to present a LPF on the basis of an application of shunt open-stubs coupled-line in the circuit of hairpin cell has been reported. However, this filter does not have a sharp transition band. In [6], defected ground structure (DGS) is utilized to design a LPF with sharp rejection, although this circuit cannot be used on the metal surface. To present a LPF with new features, rat-race directional couplers have been utilized to function as bandstop transversal filtering sections (TFSs), in [7]. However, employing this method leads to a large surface without achieving an acceptable expanded stopband. In [8], a quasi- $\pi$-slot resonator and open stubs is adopted and a LPF has been proposed, but its stopband and transition band performances are not satisfactory. A microstrip LPF using triangular and radial patch resonators has been proposed [9], but this filter suffers from gradual cut-off. To obtain a LPF featuring wide stopband, a cascaded microstrip coupledline hairpin unit and semi-circle stepped-impedance shunt stubs have been utilized, in [10]. In [11], by using LC resonant structures and transformed radial stubs a LPF has been designed. However, the proposed filters in [10] and [11] suffer from gradual roll-off rate and relatively large circuit size. Two other techniques to design LPFs with steep transition band are employing asymmetric high-low impedance patches and LC tank resonators, which have been reported in [12] and [13], respectively. In [14], a lowpass filter employing polygon patch resonant cells, $\mathrm{T}$-shaped resonators and two different suppressing cells has been designed, although, this filter does not have a steep skirt performance. One more method to present a LPF with acceptable frequency response is cascading resonators with polygon patches [15], but it occupies a large area. In [16], employing modified hairpin resonator with long straight slots leads to designing a lowpass filter with sharp skirt performance and wide rejection band, but its return loss performance is not good enough. Some other methods to present symmetric LPFs with sharp transition slope are utilizing flabelliform resonators and triangular patches [17] and [18], although these circuits suffer from a narrow stop- 
band bandwidth and large circuit size, respectively. In this letter, a microstrip lowpass filter (LPF) operating at $-3-\mathrm{dB}$ cut-off frequency of $2.1 \mathrm{GHz}$ has been designed. In the structure of the proposed filter two main resonators with semi-circle patches to create a sharp transition band and four suppressing units to reject the spurious frequencies in the frequency response have been employed.

\section{The Procedure of Designing}

This section introduces the utilized resonance cells, the procedure of analyzing their transfer functions and also explains the design process, separately. The schematic of the primary resonance cell utilizing semi-circle patch and its equivalent LC circuit have been depicted in Fig. 1. As can be observed from Fig. $1 \mathrm{~b}, L_{1 \mathrm{P}}$ is the inductance caused by the main transmission line. The employed semi-circle patch and the high-impedance transmission line are modeled by $L_{2 \mathrm{P}}$ and $C_{2 \mathrm{P}}$, respectively. Moreover, $C_{0 \mathrm{P}}$ and $C_{1 \mathrm{P}}$ represent the capacitance between the microstrip structure and the ground. Clearly, the cut-off frequency, the slope of the transition band and also the stopband bandwidth can be affected by the location and attenuation level of transition zeros. Furthermore, the impact of each employed microstrip transmission line of the resonator on the frequency response can be justified by calculating the transfer function of the equivalent LC circuit. Thus, to achieve transition zeros of the primary resonator, the transfer function based on the equivalent LC circuit will be extracted.

The equations of transfer function and transition zero of the primary resonator shown in Fig. 1b are given by (1) and (2), respectively, as follows:

$$
\begin{gathered}
\frac{V_{\mathrm{o}}}{V_{\text {in }}}=\frac{R+\left(L_{2 \mathrm{P}} C_{2 \mathrm{P}}\right) s^{2}}{R+2 L_{1 \mathrm{P}}+\left(A+B s^{2}+C s^{2}+D s^{3}+E s^{4}\right) s^{2}}, \\
A=R L_{1 \mathrm{P}}\left(C_{1 \mathrm{P}}+C_{2 \mathrm{P}}\right)+2 R\left(L_{1 \mathrm{P}} C_{0 \mathrm{P}}+L_{2 \mathrm{P}} C_{2 \mathrm{P}}\right) \\
B=L_{1 \mathrm{P}}{ }^{2}\left(C_{1 \mathrm{P}}+C_{2 \mathrm{P}}\right)+2 R L_{1 \mathrm{P}} L_{2 \mathrm{P}} C_{2 \mathrm{P}}, \\
C=R L_{1 \mathrm{P}}\left[L_{1 \mathrm{P}} C_{0 \mathrm{P}}\left(C_{1 \mathrm{P}}+C_{2 \mathrm{P}}\right)+L_{2 \mathrm{P}} C_{2 \mathrm{P}}\left(C_{1 \mathrm{P}}+C_{0 \mathrm{P}}\right)\right] \\
D=R L_{1 \mathrm{P}}{ }^{2} C_{1 \mathrm{P}} C_{2 \mathrm{P}} L_{2 \mathrm{P}} \\
E=R L_{1 \mathrm{P}}{ }^{2} C_{1 \mathrm{P}} C_{2 \mathrm{P}} L_{2 \mathrm{P}} C_{0 \mathrm{P}} \\
f_{1 \mathrm{ZP}}=\frac{1}{2 \pi} \frac{1}{\sqrt{L_{1 \mathrm{P}} C_{2 \mathrm{P}}}} .
\end{gathered}
$$

Note that $R$ in the transfer function stands for the resistance of matching. As can be observed in (7), the location of transmission zero can be controlled by altering the values of capacitance and inductance determined by $C_{2 \mathrm{P}}$ and $L_{2 \mathrm{P}}$. To illustrate the influences of changing $\mathrm{C}_{2 \mathrm{P}}$ and $\mathrm{L}_{2 \mathrm{P}}$ on the scattering parameters, their corresponding microstrip realizations can be considered instead. Thus, several full-wave simulations versus the widths and lengths of the

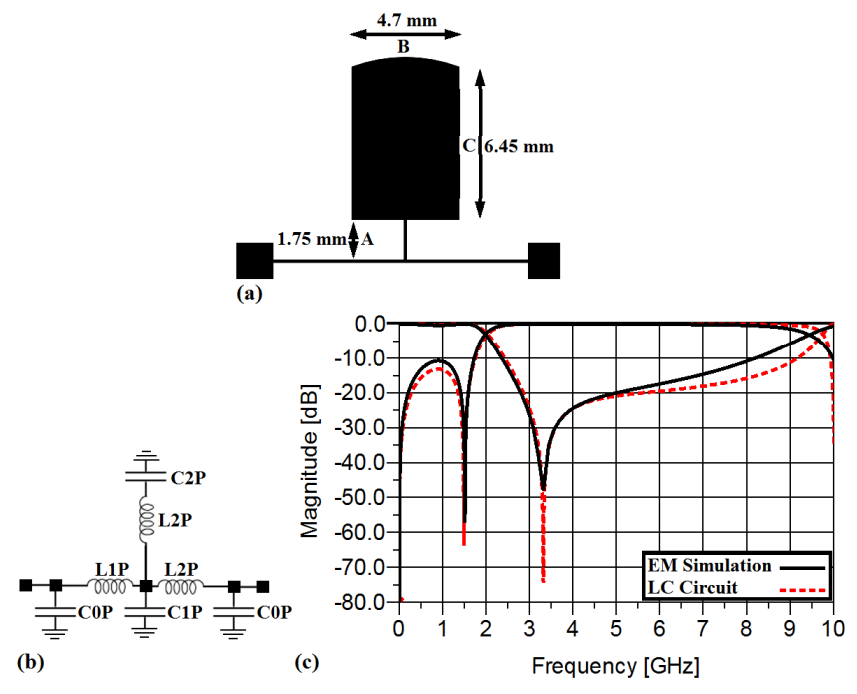

Fig. 1. (a) The configuration of the primary resonator with semi-circle patch. (b) Its equivalent LC circuit. (c) The EM simulation result and the frequency response of LC circuit of the primary structure.

transmission lines of the primary semi-circle resonator have been carried out. The behavior of the above-mentioned resonance cell against changing the values of $A, B$ and $C$ has been illustrated in Fig. 2. As it can be seen, by enhancing these variables with the shown steps, the transition zero will shift to lower frequencies creating a sharper transition band, as it was anticipated by (7). Moreover, these increases can affect the operating frequency of the resonator, as it is observed from Figs. $2 \mathrm{~b}$ and c. The values of inductors and capacitors of the shown LC circuit in Fig. $1 \mathrm{~b}$ are [19]: $L_{1 \mathrm{P}}=5.112 \mathrm{nH}, \quad L_{2 \mathrm{P}}=1.554 \mathrm{nH}$, $C_{0 \mathrm{P}}=10.5 \mathrm{fF}, C_{1 \mathrm{P}}=27.9 \mathrm{fF}, C_{2 \mathrm{P}}=1.48 \mathrm{pF}$. The result of EM simulation and the frequency response of LC circuit of the introduced resonator have been depicted in Fig. 1c.

According to the simulation results shown in Fig. 1c, the designed resonator has a $-3 \mathrm{~dB}$ cut-off frequency of $1.987 \mathrm{GHz}$. In the whole passband region, the insertion loss is almost equal to zero. Furthermore, the presented resonator has a transmission zero at $3.323 \mathrm{GHz}$ with corresponding attenuation level of $+48.059 \mathrm{~dB}$ leading to having

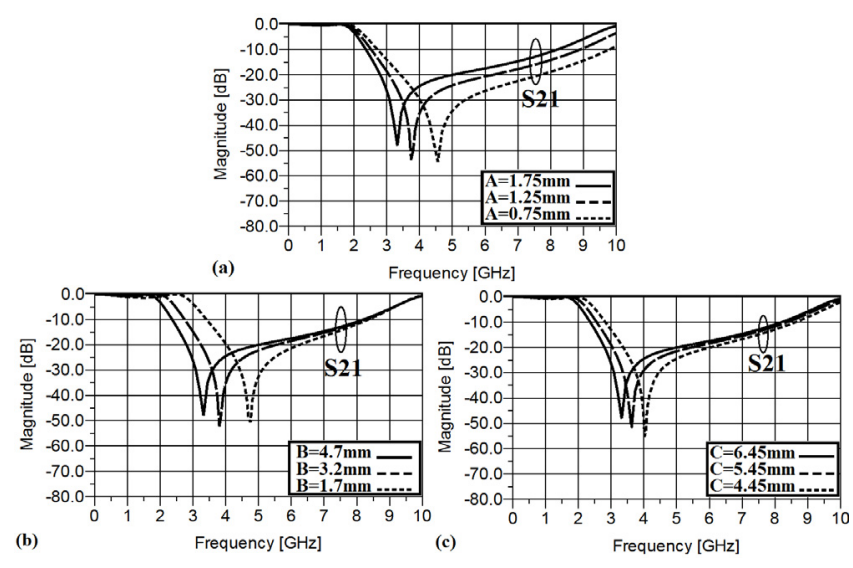

Fig. 2. The behavior of the proposed primary resonator against changing: (a) the value of $A$, (b) the value of $B$, and (c) the value of $C$. 


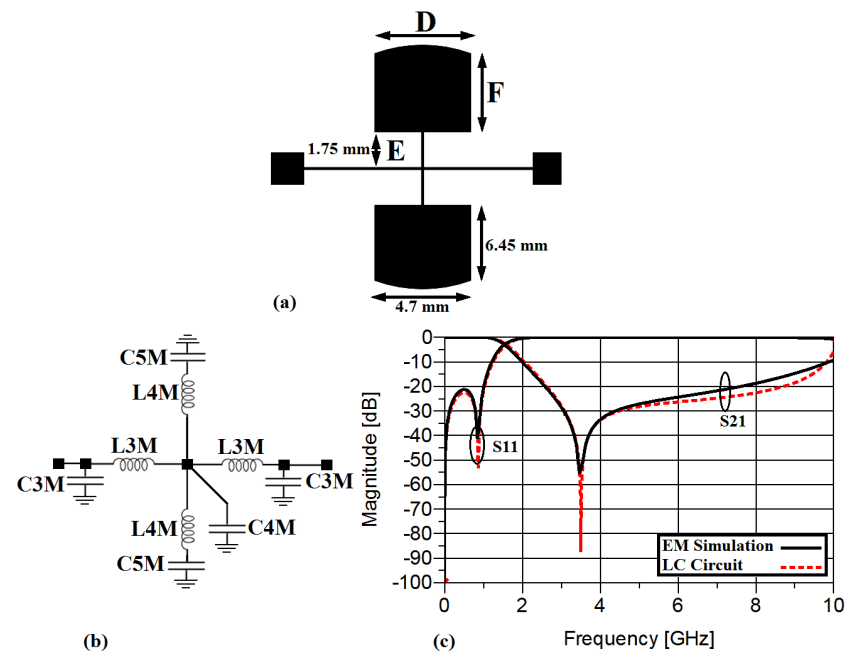

Fig. 3. (a) The configuration of the first main resonator. (b) Its equivalent lumped circuit. (c) The EM simulation result and the frequency response of LC circuit of the main structure.

an acceptable transition band. The schematic of the main resonator and its equivalent lumped circuit have been illustrated in Fig. 3. Similar to the primary resonator, to clarify how the frequency response of the resonator can be controlled, the equation of transition zero can be obtained according to Fig. $3 \mathrm{~b}$ as follows:

$$
\begin{gathered}
Z_{\text {in }}=\frac{\mathrm{j} \omega L_{4 \mathrm{M}}+\frac{1}{\mathrm{j} \omega C_{5 \mathrm{M}}}\left\|\frac{1}{2}\right\| \frac{1}{\mathrm{j} \omega C_{4 \mathrm{M}}},}{f_{2 \mathrm{ZP}}=\frac{1}{\pi} \frac{1}{\sqrt{2 L_{4 \mathrm{M}} C_{5 \mathrm{M}}}} .} .
\end{gathered}
$$

According to (9), the transition zero can be controlled by changing the values of $L_{4 \mathrm{M}}$ and $C_{5 \mathrm{M}}$. To explain the impacts of these lumped elements on the frequency response, their corresponding microstrip realizations are utilized, instead.

In order to illustrate how changing the dimensions of the mentioned corresponding microstrip lines can influence the frequency response, several full-wave simulations versus $D, E$ and $F$ have been plotted in Figs. $4 \mathrm{a}$, b and c, respectively. As it can be seen from Fig. 4, by enhancing the values of all these three variables with the determined steps, the transition zero will shift to lower frequencies creating a sharper skirt performance. Moreover, the increases in $D$ and $F$ lead to decreasing the operating frequency, but changing the value of $E$ does not have any significant effect on the cut-off frequency. The values of lumped elements of the shown LC circuit in Fig. $3 \mathrm{~b}$ are [19]: $L_{3 \mathrm{M}}=5.612 \mathrm{nH}, L_{4 \mathrm{M}}=1.554 \mathrm{nH}, C_{3 \mathrm{M}}=0.0013 \mathrm{pF}$, $C_{4 \mathrm{M}}=0.439 \mathrm{pF}$ and $C_{5 \mathrm{M}}=1.33 \mathrm{pF}$. Note that, the values of inductors and capacitances have been obtained based on RO4003 substrate with a thickness of $0.508 \mathrm{~mm}$ and the permittivity of 3.38. The EM simulation and the frequency response of the lumped circuit of the main resonator have been depicted in Fig. 3c, which are in good agreement.

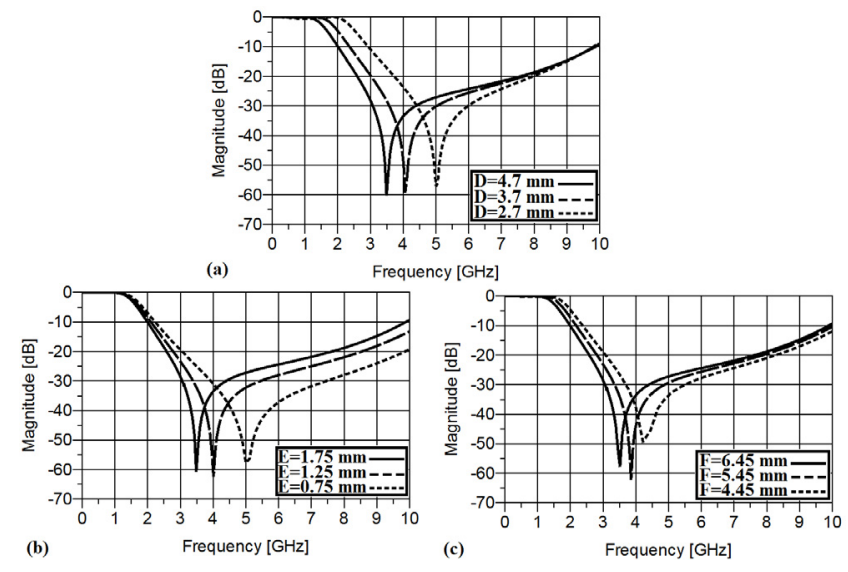

Fig. 4. The behavior of the main resonator against changing (a) the value of $D$, (b) the value of $E$ and (c) the value of $F$.

As can be observed, the return loss and insertion loss in the passband region are almost +21.331 and $+0.069 \mathrm{~dB}$, respectively. Moreover, the first main resonance cell makes a transition zero at $3.467 \mathrm{GHz}$ with an attenuation level of $+55.717 \mathrm{~dB}$. Thanks to this transmission zero a suppressing band covering an acceptable frequency range from 2.257 to $8.637 \mathrm{GHz}$ with corresponding attenuation level of $15 \mathrm{~dB}$ has been obtained. Obviously, the main resonator suffers from gradual skirt performance and also a poor stopband characteristic.

The schematic of the second main resonance cell employing another form of semi-circle patch and its equivalent LC circuit are depicted in Fig. 5a and b. To control the frequency response characteristics of this resonator, the impacts of variables on the frequency response should be determined like the first main resonator. Thus, the equations of transfer function and transmission zeros of the resonator shown in Fig. 5 a based on its LC circuit have been extracted as follows:

$$
\begin{gathered}
\frac{V_{\mathrm{o}}}{V_{\text {in }}}=\frac{R Z_{0} Z_{2}\left(Z_{C}{ }^{2}+Z_{3}{ }^{2}+Z_{4}{ }^{2}\right)}{\left(R+L_{0}\right)\left(G^{\prime}+2 Z_{\mathrm{C}}{ }^{2} H^{\prime}\right)+R Z_{0} Z_{1} K^{\prime}}, \\
G^{\prime}=\left(Z_{1}^{2}-Z_{2}{ }^{2}\right)\left(Z_{3}^{2}-Z_{4}{ }^{2}\right)-Z_{\mathrm{C}}{ }^{4}, \\
H^{\prime}=Z_{3} Z_{2}-Z_{1} Z_{4}, \\
K^{\prime}=\left(Z_{4}{ }^{2}-Z_{3}{ }^{2}\right)-Z_{0}{ }^{4} Z_{\mathrm{C}}{ }^{2}, \\
Z_{0}=\frac{1}{L_{0} s}, \quad Z_{1}=C_{2} s+\frac{1}{L_{0} s}+\frac{2}{L_{2} s}+\frac{1}{L_{1} s}, \\
Z_{2}=\frac{1}{L_{1} s}, \quad Z{ }_{3}=2 C_{\mathrm{g}} s, \quad Z_{\mathrm{C}}=\frac{2}{L_{2} s}, \\
Z_{4}=\frac{2}{L_{2} s}+2\left(C_{\mathrm{g}}+C_{1}\right) s, \\
f_{3 Z \mathrm{P}}=\frac{1}{2 \pi} \sqrt{\frac{q-\sqrt{w}}{u}},
\end{gathered}
$$




$$
\begin{gathered}
f_{4 \mathrm{ZP}}=\frac{1}{2 \pi} \sqrt{\frac{q+\sqrt{w}}{u}}, \\
Z_{0}=C_{1} L_{2}+C_{\mathrm{g}} L_{1}+C, \\
w=2 C_{1} L_{2} C_{\mathrm{g}} L_{1}+C_{\mathrm{g}} 2 L_{1}^{2}+C_{\mathrm{g}}, \\
u=C_{1}^{2} L_{2}^{2}+2 C_{\mathrm{g}} C .
\end{gathered}
$$

Likewise, the influences of changing the values of the valuables determined in (10)-(21) affecting the transfer function and the transmission zeros can be studied on the basis of their corresponding microstrip realizations. As it is clear, the values of $L_{1}, L_{2}, C_{1}$ and $C_{\mathrm{g}}$ can be utilized to control the location of transition zeros of the second main resonator, effectively. Therefore, to study their impacts on the frequency response of the depicted resonator in Fig. 5a, the dimensions of their corresponding microstrip realizations have been changed.

Several full-wave simulations versus the most effective dimensions, i.e. $G, H$ and $K$ have been plotted in Fig. 6. As it can be seen, by enhancing the above-mentioned values with the shown steps, the both transition zeros will move to lower frequencies leading to creating a sharper transition band. Note that, with the exception of the value determined by $K$, by increasing the dimensions of the semi-circle patches, the operating frequency of the second resonator will shift to lower frequencies. As it can be seen from the simulation results illustrated in Fig. 5c, the operating frequency of the presented resonator with semi-circle patches is located on $2.08 \mathrm{GHz}$.

The stopband of the designed resonator rejects spurious frequencies from $2.32 \mathrm{GHz}$ to $7.682 \mathrm{GHz}$ with corresponding attenuation level of $15 \mathrm{~dB}$. The insertion loss is around $+0.092 \mathrm{~dB}$ from $\mathrm{DC}$ to $1.78 \mathrm{GHz}$ which proves
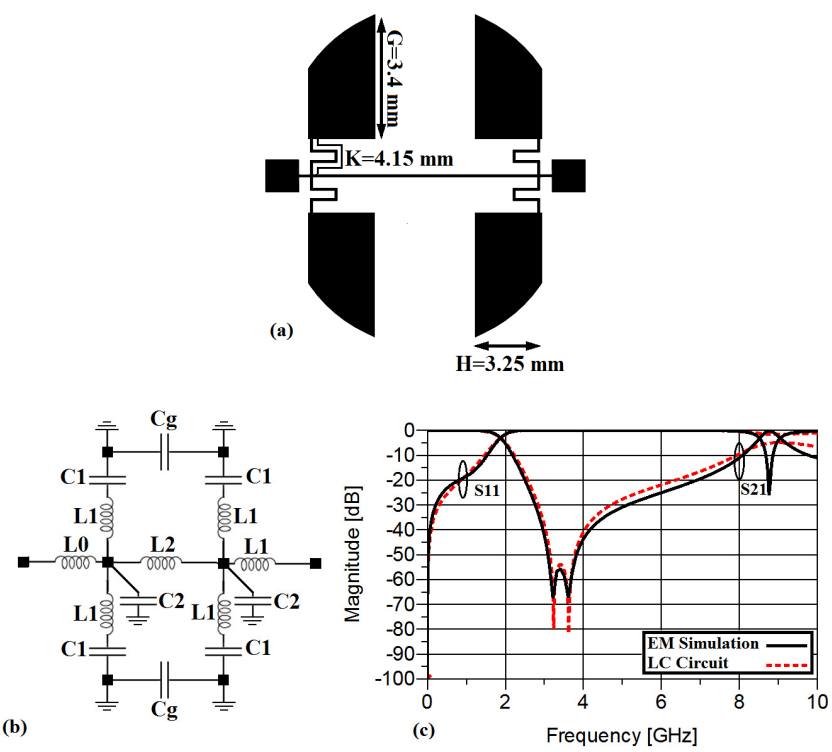

Fig. 5. (a) The configuration of the second main resonator with different semi-circle patches. (b) Its equivalent LC circuit. (c) The EM simulation result of the resonator and the frequency response of its LC circuit.
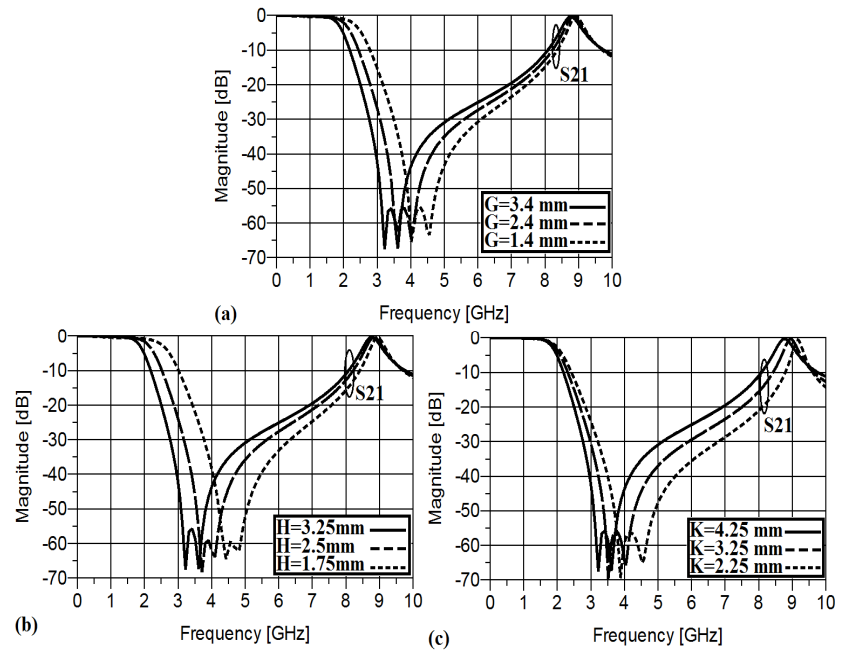

Fig. 6. The behavior of the second main resonator against changing (a) the value of $G$, (b) the value of $H$ and (c) the value of $K$.

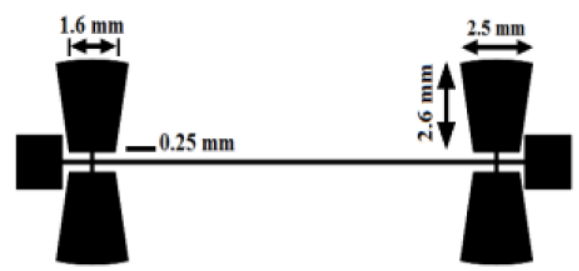

(a)

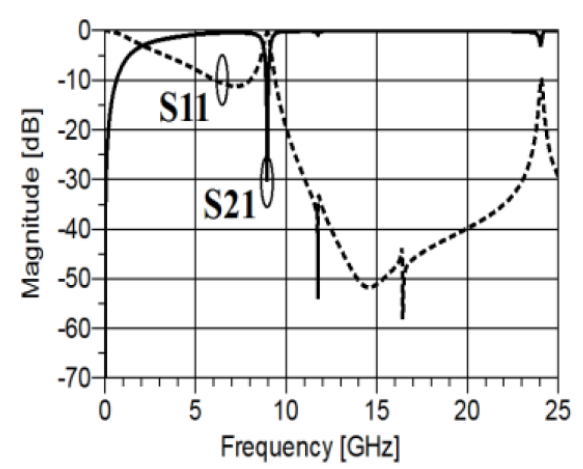

(b)

Fig. 7. (a) The configuration of the suppression units using high-low impedance resonators with radial patches, (b) its frequency response.

a desired response in the pass band. Furthermore, the proposed resonator makes two transmission zeros at $3.223 \mathrm{GHz}$ and $3.613 \mathrm{GHz}$ with corresponding attenuation levels of $+67.591 \mathrm{~dB}$ and $+67.417 \mathrm{~dB}$, respectively, leading to having an acceptable stopband characteristic. However, to widen the stopband region, suppressing cells are required.

Utilizing these suppressing units makes some transmission nulls, thus transmission peaks will be suppressed and consequently the stopband region will be expanded. One of the most influential suppression cells to extend the stopband bandwidth is high-low impedance resonator with radial patches. Figure $7 \mathrm{a}$ and $\mathrm{b}$ illustrates the schematic and the frequency response of these suppressing cells. As it can be seen from the frequency response, the designed suppressing cell creates three transition zeros at $11.75 \mathrm{GHz}$, 


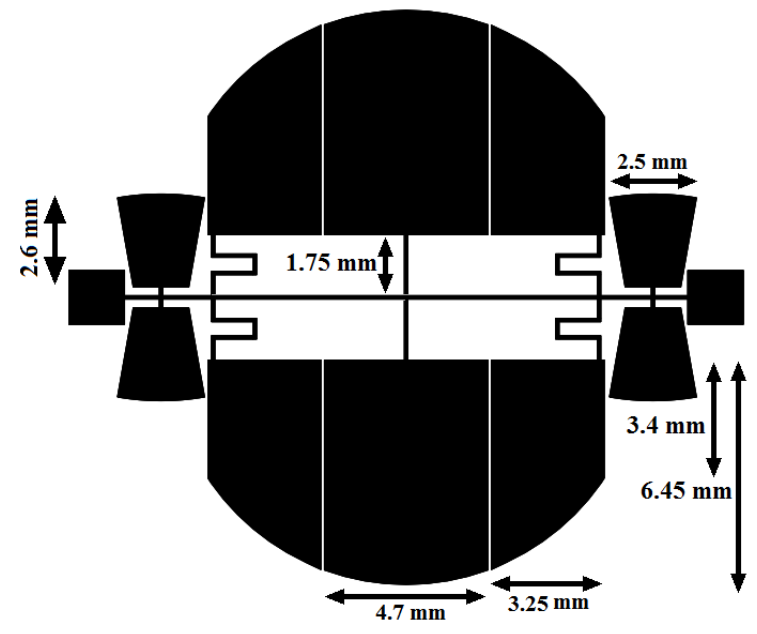

Fig. 8. The configuration of the proposed lowpass filter.

15.61 GHz and $16.44 \mathrm{GHz}$ with corresponding attenuation levels of +53.769 , +51.758 and $+57.922 \mathrm{~dB}$. Owing to these transition zeros, the stopband of this cell can suppress spurious frequencies from 10 to $23.78 \mathrm{GHz}$ with a desired level of suppression.

Finally, by combining the first, second and the designed suppressing resonators, a microstrip LPF with $-3 \mathrm{~dB}$ cut-off frequency of $2.1 \mathrm{GHz}$ has been designed.

Furthermore, the presented LPF has a transmission zero around the cut-off frequency, which leads to an acceptable skirt performance. In addition, a suppressing factor equal to $32.14 \mathrm{~dB}$ over the illustrated frequency range has been achieved.

\section{The Results of Simulation and Measurement}

The photograph of the proposed LPF has been depicted in Fig. 9a. The presented LPF has been designed, constructed and measured. The fabricated LPF has been constructed on a substrate with the thickness of $0.508 \mathrm{~mm}$, the permittivity of 3.38 and the loss tangent of 0.0021 . The results of simulation and measurement of the scattering parameters have been illustrated in Fig. 9b. As it can be observed, the $-3 \mathrm{~dB}$ operating frequency of the filter has been placed on $2.1 \mathrm{GHz}$. In the entire passband region the insertion loss is close to $+0.1 \mathrm{~dB}$ from $\mathrm{DC}$ to $1.855 \mathrm{GHz}$, which indicates a flat response. As it can be seen, close to the cut-off frequency two transmission zeros (TZs) at 2.382 and $2.897 \mathrm{GHz}$ are created which lead to a steep transition band. Owing to these TZs, a sharp roll-off rate equal to $(203.57 \mathrm{~dB} / \mathrm{GHz})$ has been obtained, which proves a desired skirt performance.

The stopband region covers a wide range, suppressing spurious frequencies from 2.294 up to $21.95 \mathrm{GHz}$ with corresponding rejection level of $32 \mathrm{~dB}$. Table 1 illustrates the performance comparison of the other published works and the proposed LPF.

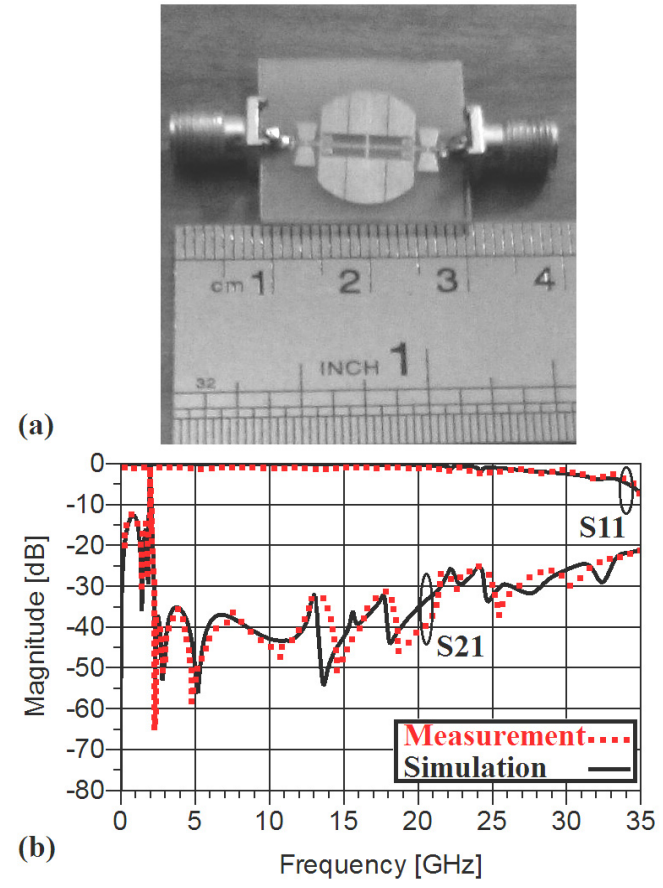

Fig. 9. (a) The photograph of the proposed LPF. (b) Its frequency response.

\begin{tabular}{|c|c|c|c|c|c|c|}
\hline Ref. & $\zeta$ & $R S B$ & $S F$ & NCS & $A F$ & $F O M$ \\
\hline$[1]$ & 36.3 & 1.323 & 1.5 & $0.079 \times 0.079$ & 1 & 11543 \\
\hline$[2]$ & 37 & 1.15 & 2 & $0.280 \times 0.076$ & 1 & 3999 \\
\hline$[3]$ & 30 & 1.25 & 1.5 & $0.080 \times 0.080$ & 1 & 8789 \\
\hline$[4]$ & 74 & 1.19 & 2 & $0.114 \times 0.105$ & 1 & 14713 \\
\hline$[5]$ & 95 & 1.4 & 2 & $0.214 \times 0.104$ & 1 & 11951 \\
\hline$[6]$ & 130 & 0.933 & 2 & $0.227 \times 0.089$ & 2 & 6004 \\
\hline$[7]$ & 200 & 1.36 & 2 & $0.801 \times 0.374$ & 1 & 1815.9 \\
\hline$[8]$ & 82 & 1.28 & 2.5 & $0.110 \times 0.220$ & 1 & 10842 \\
\hline$[9]$ & 37 & 1.65 & 1.5 & $0.111 \times 0.091$ & 1 & 9065 \\
\hline$[10]$ & 61.6 & 1.44 & 1 & $0.272 \times 0.236$ & 1 & 1386 \\
\hline$[11]$ & 62 & 1.72 & 3 & $0.310 \times 0.240$ & 1 & 4430 \\
\hline$[14]$ & 185 & 1.666 & 2.1 & $0.227 \times 0.177$ & 1 & 16181 \\
\hline$[17]$ & 74.7 & 1.396 & 3 & $0.166 \times 0.175$ & 1 & 10769.14 \\
\hline $\begin{array}{c}\text { This } \\
\text { Work }\end{array}$ & $\mathbf{2 0 3 . 5 7}$ & $\mathbf{1 . 6 1}$ & $\mathbf{3 . 2}$ & $\mathbf{0 . 2 0 8} \times \mathbf{0 . 2 0 8}$ & $\mathbf{1}$ & $\mathbf{2 4 2 4 1 . 6 9}$ \\
\hline
\end{tabular}

Tab. 1. The comparison of the abilities of the proposed LPF and previous works.

In the shown table the roll-off rate $\xi$ is defined as follows:

$$
\xi=\frac{\alpha_{\max }-\alpha_{\min }}{f_{\mathrm{S}}-f_{\mathrm{C}}}(\mathrm{dB} / \mathrm{GHz}) .
$$

In this equation $\alpha_{\max }$ is the $40 \mathrm{~dB}$ attenuation point, $\alpha_{\min }$ is the $3 \mathrm{~dB}$ attenuation point, $f_{\mathrm{S}}$ is the $40 \mathrm{~dB}$ stop-band frequency, and $f_{\mathrm{C}}$ is the $-3 \mathrm{~dB}$ cutoff frequency.

The relative stop-band bandwidth $(R S B)$ is defined as shown below:

$$
R S B=\frac{\text { stop-band } \quad \text { bandwidth }(-20 \mathrm{~dB})}{\text { stop-band center frequency }} .
$$

The suppression factor $(S F)$ is defined as shown in (24). For example, when the stop-band suppression is $32 \mathrm{~dB}$, the corresponding $S F$ will be 3.2 . 


$$
S F=\frac{\text { stop-band supression }}{10 \mathrm{~dB}}
$$

The normalized circuit size (NCS) is given by:

$$
N C S=\frac{\text { physical } \quad \text { size }(\text { length } \times \text { width })}{\lambda_{\mathrm{g}}^{2}}
$$

where $\lambda_{\mathrm{g}}$ is the guided wavelength at $-3 \mathrm{~dB}$ cut-off frequency.

The architecture factor $(A F)$ denotes the circuit complexity. When we have a two-dimensional design, we define $A F=1$. Similarly, for three-dimensional designs, we have $A F=2$. follows:

At the end, the figure-of-merit $(F O M)$ is defined as

$$
F O M=\frac{\xi \cdot R S B \cdot S F}{N C S \cdot A F} .
$$

Based on the above definitions, it is easily understood that, the calculated roll-off rate $\xi, R S B, S F, N C S$ and $A F$ of the proposed filter lead to a figure-of-merit equal to 24241.69 .

As it can be observed, the skirt performance of the designed filter is sharper than the other published articles, which is because of the combination of the first and second resonators. Utilizing the depicted suppressing unit shown in Fig. 7a, leads to obtaining an acceptable relative stopband bandwidth RSB, which is 1.78 . The closest RSB to this have been cited in [9], [11] and [14] $(1.65,1.72$ and 1.666 , respectively). The suppressors suppress spurious frequencies with a suppressing factor of $32 \mathrm{~dB}$, which is better than the other works. Clearly, the proposed filters in [11] and [17] have the closest suppressing factor to this work. As it can be observed, the presented filter, in spite of occupying $262.44 \mathrm{~mm}^{2}$ at the operating frequency of $2.1 \mathrm{GHz}$, has brought about a figure of merit equal to 24241.69 , which is much more than the other published articles.

\section{Conclusion}

A low pass filter using semi-circle patch resonant cells and four suppressing cells with high-low impedance patches has been proposed and fabricated. According to the equivalent $\mathrm{LC}$ circuit of each resonator, the locations of transition zeros of the mentioned resonance cells have been calculated. The frequency response verifies a good in-band and out-band performances based on the measurement results. The proposed lowpass filter demonstrates a sharp skirt performance, a wide rejection band, low insertion loss and low return loss in the passband region and also occupies a small area $\left(16.2 \times 16.2 \mathrm{~mm}^{2}\right)$. According to the measurement results, the figure of merit of the proposed filter is equal to 24241.69 .

\section{References}

[1] WANG, J., XU, L. J., ZHAO, S., GUO, Y. X., WU, W. Compact quasi-elliptic microstrip lowpass filter with wide stopband. Electronics Letters, 2010, vol. 46, no. 20, p. 1384-1385. DOI: $10.1049 / \mathrm{el} .2010 .1569$

[2] LUO, S., ZHU, L., SUN, S. Stopband-expanded low-pass filters using microstrip coupled-line hairpin units. IEEE Microwave and Wireless Components Letters, 2008, vol. 18, no. 8, p. 506-508. DOI: 10.1109/LMWC.2008.2001004

[3] WEI, X. B., WANG, P., LIU, M. Q., SHI, Y. Compact widestopband lowpass filter using stepped impedance hairpin resonator with radial stubs. Electronics Letters, 2011, vol. 47, no. 15, p. 862-863. DOI: $10.1049 / \mathrm{el} .2011 .1414$

[4] LI, L., LI, F. Z., MAO, F. J. Compact lowpass filters with sharp and expanded stopband using stepped impedance hairpin units. IEEE Microwave and Wireless Components Letters, 2010, vol. 20, no. 6, p. 310-312. DOI: 10.1109/LMWC.2010.2047457

[5] VELIDI, V. K., SANYAL, S. Sharp roll-off lowpass filter with wide stopband using stub-loaded coupled-line hairpin unit. IEEE Microwave and Wireless Components Letters, 2011, vol. 21, no. 6 , p. 301-303. DOI: 10.1109/LMWC.2011.2132120

[6] MANDAL, M. K., MANDAL, P., SANYAL, S., et al. Low insertion-loss, sharp rejection and compact microstrip lowpass filter. IEEE Microwave and Wireless Components Letters, 2006, vol. 16, no. 11, p. 600-602. DOI: 10.1109/LMWC.2006.884777

[7] GOMEZ-GARCIA, R., SANCHEZ-SORIANO, M. A., SANCHEZ RENEDO, M., et al. Extended-stopband microstrip lowpass filter using rat-race directional couplers. Electronics Letters, 2013, vol. 49, no. 4, p. 272-274. DOI: 10.1049/el.2012.4245

[8] WANG, C. J., LIN, C. H. Compact lowpass filter with sharp transition knee by utilising a quasi- $\pi$-slot resonator and open stubs. IET Microwaves Antennas and Propagation, 2010, vol. 4, no. 4, p. 512-517. DOI: 10.1049/iet-map.2009.0001

[9] WANG, J., CUI, H., ZHANG, G. Design of compact microstrip lowpass filter with ultra-wide stopband. Electronics Letters, 2012, vol. 48, no. 14, p. 854-856. DOI: 10.1049/el.2012.1362

[10] WEI, F., CHEN, L., SHI, X. W., et al. Compact lowpass filter with wide stop-band using coupled-line hairpin unit. Electronics Letters, 2010, vol. 46, no. 1, p. 88-90. DOI: 10.1049/el.2010.2411

[11] MA, K., YEO, K. S. New ultra-wide stopband low-pass filter using transformed radial stubs. IEEE Transactions on Microwave Theory and Techniques, 2011, vol. 59, no. 3, p. 604-611. DOI: 10.1109/TMTT.2010.2095031

[12] ABDIPOUR, AS., ABDIPOUR, AR., LOTFI, S. A lowpass filter with sharp roll-off and high relative stopband bandwidth using asymmetric high-low impedance patches. Radioengineering, 2015 , vol. 24, no. 3, p. 712-716. DOI: 10.13164/re.2015.0712

[13] NOURITABAR, A. R., ABDIPOUR, AS., ABDIPOUR, AR. A design of low-pass filter with wide stopband and sharp roll-off rate using series LC tanks resonator. Applied Computational Electromagnetics Society (ACES) Journal, 2016, vol. 31, no. 11, p. 1343-1350. ISSN: 1054-4887

[14] ABDIPOUR, AR., ABDIPOUR, AS. Compact microstrip lowpass filter with an ultra-wide stopband and sharp transition band using T-shaped and polygon resonators. Progress In Electromagnetics Research C, 2017, vol. 74, p. 51-61. DOI: 10.2528/PIERC16121904

[15] ABDIPOUR, AR., ABDIPOUR, AS., LORESTANI, F. A compact microstrip lowpass filter with sharp roll-off rate and ultra-wide stopband employing coupled polygon patches. Progress In Electromagnetics Research C, 2017, vol. 76, p. 171-183. DOI: 10.2528/PIERC17043003 
[16] ABDIPOUR, AS., NOURITABAR, A. R., ABDIPOUR, AR., et al. A miniaturized microstrip lowpass filter with sharp skirt performance and wide stopband utilizing modified hairpin resonator with long straight slots. Progress In Electromagnetics Research C, 2017, vol. 78, p. 83-92. DOI: 10.2528/PIERC17072706

[17] ABDIPOUR, AS., ABDIPOUR, AR. Compact microstrip lowpass filter with high and wide rejection in the stopband utilizing flabelliform resonators. Progress In Electromagnetics Research M, 2017, vol. 60, p. 179-188. DOI: 10.2528/PIERM17072803

[18] ABDIPOUR, AS., ABDIPOUR, AR., KOSRAVI, A. A compact microstrip lowpass filter with ultra-wide rejection band and sharp transition band utilizing combined resonators with triangular patches. Radioengineering, 2018, vol. 27, no. 2, p. 417-424. DOI: $10.13164 / \mathrm{re} .2018 .0417$

[19] HONG, J. S., LANCASTER, M. J. Microstrip Filters for $R F /$ Microwave Applications. $1^{\text {st }}$ ed. John Wiley \& Sons, Inc., 2001. ISBN 0-471-22161-9. DOI:10.1002/0471221619

\section{About the Authors ...}

Ashkan ABDIPOUR received the B.S in Electronics
Engineering, from Islamic Azad University, KermanshahBranch, Kermanshah, Iran, in 2009 and the M.S degree from Razi University, Kermanshah, Iran, in 2013. His research interest includes Microwave and millimeter wave devices and circuits.

Arash ABDIPOUR received the B.S in Electronics Engineering, from Islamic Azad University, Kermanshah Branch, Kermanshah, Iran, in 2009 and Master's degree in Electronics Engineering from the Kermanshah-science and research University of Kermanshah Branch, Kermanshah, Iran, in 2013. His research interest includes Microwave and millimeter wave devices and circuits.

N. ALAHVERDI received the B.S in Electronics Engineering, from Islamic Azad University, Kermanshah Branch, Kermanshah, Iran, in 2009 and Master's degree in Electronics Engineering from the Kermanshah-science and research University of Kermanshah Branch, Kermanshah, Iran. Her main research interest includes microstrip lowpass filters. 